\title{
Fostering the Development of ESL/ASL Bilinguals
}

\section{Charlotte J. Evans and Kelvin L. Seifert}

This article provides a bilingual perspective about literacy development in deaf students and uses the bilingual perspective to recommend effective teaching strategies for this group of students with special needs. In the case of deaf students, however, the bilingualism is not between two oral languages, but between American Sign Language (ASL) and written English. The analogy of Deaf education to bilingual education is imperfect, as the article shows, but nonetheless helpful in suggesting educational strategies. One difference from classic bilingual education is the difference in mode of the two languages, with ASL using a haptic mode (signing) and written English using a visual mode. Another difference is the nontraditional nature of Deaf communities. Although ASL communities certainly have histories and traditions, Deaf individuals rarely learn these from family ties or immersion in a kinship-based culture that "speaks" ASL. Despite these differences in language mode and cultural transmission, teaching deaf students benefits from many strategies usually associated with the teaching of second languages, including fostering motivation, developing selfconcepts, understanding language development, knowing elements of a student's first language, allowing judicious translation, focusing on comprehension rather than syntax, and incorporating cultural values and native speakers-signers as role models.

Applying a bilingual model to the education of deaf ${ }^{1}$ students involves viewing Deaf people from a cultural perspective, which is best understood in a framework that outlines the significant changes and developments in the field of Deaf education.

The development of age-appropriate literacy skills in deaf children has been a challenge for parents and educators for hundreds of years. There are good historical reasons for the literacy impairment of deaf children. Before the 1970s, the education of deaf children in Canada occurred through almost exclusively oral methods. This approach primarily emphasized the use of amplification (hearing aids) to develop speaking and listening skills. The educational focus was to remediate the deficits of deaf children to help them become more like hearing people.

Frequently this emphasis on speech skills took precedence over facilitating non-oral language development and teaching deaf people to become literate. 
Simultaneous communication-speaking and signing at the same timewas introduced and flourished in the 1970s. This method of communication used signs from American Sign Language (ASL), but presented them in the word order of spoken English. Some signs were invented to match English words more directly, and frequently grammatical markers and word endings were added to signs to reflect English grammatical structures. The purpose of using this method of communication in the classroom was to expose deaf children to a visual model of English and thereby facilitate their development of spoken and written English. In theory, the notion of altering a language to reflect the written code more accurately should facilitate the acquisition of the written form.

However, the use of simultaneous communication, or sign-supported speech, has two major flaws. First, the appropriateness of altering language for instruction is questionable. Programs teaching French to English-speaking children or adults do not facilitate this instruction by first introducing French words in English word-order or French words with English grammatical endings. It is appropriate to draw comparisons between the two languages, but not to alter existing grammatical rules and structures (Genesee, 1994). Second, it must be questioned whether English as a spoken language can accurately be represented in manual form. It was effectively documented that many of the grammatical structures of English were not included in teachers' use of English-based signing (Johnson, Liddell, \& Erting, 1989). For these reasons, during the 1980s educators and researchers began to realize that simultaneous communication was not having the desired effect on the educational outcome of deaf students. The overall reading level of high school graduates had not increased beyond the previous level of grade 4 (Meadow, 1972).

One group of deaf children, however, consistently scored higher on tests of English reading skills than their deaf peers with hearing parents: those with Deaf parents. These children, it seemed, became fully immersed in ASL and treated it as their first language. Written English was therefore learned as if it was a second language, and these Deaf children became essentially bilingual (Hoffmeister \& Wilbur, 1980). The importance of establishing a first language in the successful development of a second language is supported in the bilingual education literature (Wong Fillmore, 1991). The observations of Deaf students with Deaf parents established the premise that deaf children should learn ASL as a first language and English should be introduced as a second language, and that deaf education should be a form of bilingual education. The how, when, and who of implementing ASL-English bilingualism, however, continue to be debated and delineated.

Deaf children may access text as do children who are learning English as a second language, although the processes are not parallel. Hearing children learning English as a second language frequently learn to speak English 
before or while they learn to read it, whereas deaf children learn English through reading it (Yurkowski \& Ewoldt, 1986). The advocates of teaching English as a second language to deaf children emphasize the importance of first establishing a language base in a natural and accessible language (Erting, 1992; Evans, 1999; Johnson et al., 1989; Mahshie, 1995). Overall, there is agreement that early exposure to ASL allows deaf children to establish an effective way to communicate and interact with the world around them (Paul \& Quigley, 1987). Disagreements arise in how this knowledge should be applied to guide them into reading and writing English. Hearing people have the advantage that the correspondence between the written pieces and the retrievable speech patterns follow the same linguistic structure. Additional translation steps are needed for the deaf learner. The exact nature of these steps and how to facilitate their development have yet to be defined.

The theories of bilingual and biliterate education can be applied to programs educating deaf students, but a shift from a deficit to a cultural perspective of deaf students is needed. Several schools and programs for deaf children in Canada are making this change in perspective and have adopted a bilingual/bicultural philosophy (Israelite, Ewoldt, \& Hoffmeister, 1992). However, a gap remains between the theoretical aspects of this philosophy and the practical aspects of its implementation. Teachers continue to question if they can use their students' knowledge of ASL to develop and promote the English literacy skills of these deaf children. We know that deaf children who grow up in an ASL environment learn ASL in ways analogous to hearing children learning their spoken language (Meier, 1991; Pettito \& Marentette, 1991). What we do not know is how deaf children learn English or how they learn to read and write it. There is now growing evidence from case studies (Evans, 1999; Wilcox, 1994) to support bilingually focused, alternative conceptions and pedagogies as successful in the language and literacy education of deaf children, and the evidence deserves further exploration.

\section{Bilingualism of Oral Languages}

An understanding of bilingual education with deaf children builds on the general study of bilingualism. For most of the history of the study of language development, bilingualism in North America was considered a disadvantage to children cognitively, intellectually, and educationally (Reynolds, 1991). This attitude began to change, however, as a result of a landmark study by Peal and Lambert (1962). Using standardized assessment of FrenchEnglish bilingual children, these researchers suggested that bilingual children, in comparison with unilingual children, demonstrated increased mental flexibility, superiority in concept formation, and a more diversified set of mental abilities. These conclusions were supported by Vygotsky's (1978) sociocultural learning theory, which emphasizes the significance of language as the primary mediator in learning about the world. Vygotsky suggested 
that through bilingualism the child could view phenomena under more general categories, see each language as a particular system among many, and ultimately gain an awareness of linguistic operations.

Because the work of Peal and Lambert (1962), other research studies have tended to emphasize the benefits of bilingualism and bilingual education programs (Reynolds, 1991). Research on bilingualism expanded from describing the cognitive benefits to describing the psycholinguistic effects, such as the relationship between the two languages and their mental representations. In general, the psycholinguistic research suggests that bilingual people display both independent and interdependent functioning between languages. It therefore also proposes that their underlying cognitive systems are structurally separate and yet interconnected (Paivio, 1991).

The paradox of bilingual functioning as both independent and interdependent is resolved by considering mental representation models in which each language is stored separately but linked with a common conceptual core. This assumption plays a significant role in bilingual educational programs, because it suggests a common underlying proficiency. It also implies that experience with either language can promote the proficiency underlying both languages. The common proficiency exists not at the surface levels (pronunciation, grammar, vocabulary) of the first and second languages, but at the deeper conceptual levels (Cummins, 1984). It facilitates the transfer of cognitive, academic, or literacy-related skills across languages. The skills would include conceptual knowledge, subject matter knowledge, higher-order thinking skills, reading strategies, and writing composition skills.

\section{Bilingualism and Deaf Children}

Research on bilingual education programs for hearing children in North America has been carried out for several decades. Although there continues to be discussion regarding the timing of language acquisition and exposure and its impact on academic achievement, there is general agreement that fully bilingual students enjoy cognitive advantages over monolinguals (Collier, 1989). The idea of deaf education as a form of bilingual education is relatively recent (Strong, 1988). The movement to teach English to deaf students as a second language came out of the research documenting natural sign languages of the Deaf as languages (Baker \& Battison, 1980; Johnson et al., 1989). As this research became widely known, Deaf people in Canada and the United States identified themselves as a linguistic minority rather than a disabled group. The identity of Deaf people as minority language users also linked deaf education with ESL research and teaching strategies. For Deaf students, like many immigrant children, knowledge of English is not only an advantage as a second language, but a necessity as the majority language (Edelsky, 1989). Gradually the shift to cultural affiliation has influenced deaf 
education by shifting its focus from special education to bilingual education and the incorporation of an ESL approach.

Bilingual Deaf Education (BDE) differs significantly from other bilingual programs. One difference is language mode. Proponents of BDE advocate that students' first language be a natural visual-spatial language such as ASL (Davies, 1991; Johnson et al., 1989). Such a language, they argue, functions and is represented mentally analogously to spoken languages.

Linguistic analysis of ASL shows that it is a complex, structured language with distinct grammar and that it exhibits the fundamental properties that linguists have posited for all languages (Klima \& Bellugi, 1979). The properties are manifested in distinctive structural characteristics of simultaneity and the use of space. Simultaneity means that grammatical features tht involve movement and facial expression can be produced at the same time as the root sign and thereby add to, or alter, its meaning. These modifications to sign production do not simply provide paralinguistic information, but are morphological markers in ASL. Thus several morphemes are expressed at once. Points in space are used to refer to people, things, and places that are not present. The linguistic structures of ASL are adapted to maximize visual processing, visual memory, and manual dexterity. ASL uses simultaneity and space to convey similar concepts that depend on a sequential transmission of sounds in spoken language. In the visual mode, stimuli that occur simultaneously can be perceived in a meaningful way, whereas in the auditory mode, stimuli must be perceived sequentially in order to be meaningful, because when two sounds occur together often only the louder one is perceived. ASL is uniquely adapted to capitalize on the processing differences between visual and auditory modes by using space and motion whereas spoken language uses time for the same purpose.

Studies examining the linguistic features of ASL show that ASL functions in the same way as spoken languages. It allows people to request, command, argue, persuade, and tell jokes. More abstractly, it functions not only as a linguistic system, but as a purveyor of culture, a representation of the real, a means for exerting or resisting power and control, a homeland, and a marker of identity (Kouritzin, 1999). Further evidence that ASL is a bona fide language exists in the study of its acquisition by children, both Deaf and hearing, with Deaf parents. In these children language acquisition parallels that of children learning spoken languages; children of Deaf parents, for example, also experience periods of over- and undergeneralization of ASL rules, just as children learning English do (Meier, 1991).

Although ASL does not result in a difference in linguistic function or developmental processes, the question of a difference in mental representation remains, particularly as ASL uses visual and spatial rather than auditory skills. This issue was addressed by Bellugi, Poizner, and Klima (1989) by studying the cognitive and language skills of Deaf people suffering 
left- and right-sided brain lesions. They found that the left cerebral hemisphere in these persons was specialized for signed language, just as the left cerebral hemisphere of hearing people is specialized for spoken language. The researchers argued, further, that the left hemisphere appears to be innately predisposed for language, as well as independent of language mode. Neurologically, therefore, ASL may function much as a "verbal" language. Although its surface structures are significantly different from those of spoken languages, ASL at a deeper level is related to the same conceptual core or common underlying proficiencies.

The difference in mode between spoken and written English may also influence deaf children's acquisition of English literacy. Although hearing children learn to read by forming sound-symbol associations, learning to read without forming such associations is necessary, and we hope possible, for deaf children. In other words, being a symbol without being mediated by the sound system should be possible for a visually represented pattern. This is the case for mathematical "sentences." The symbols can be verbalized through the sound system; however, this frequently inhibits, rather than helps, the processing of the "sentences." The written symbols appear to map directly to mental concepts without being mediated by speech.

Further insight into learning to read can be gained by considering orthographies that are syllable-based and therefore less dependent on phonetic associations. In the case of Japanese, for example, Hatano (1986) states that an experienced reader of Japanese uses several different internal codes for a word. He explains Japanese orthography as having two distinct written systems, one linked with pronunciation (called kana) and the other linked with meaning (kanji). Meaning is achieved by the Japanese reader directly through the kanji symbols, but can also be mediated through the kana symbols and the phonetic code. The Japanese experience suggests that similar processes might occur in Deaf readers reaching meaning from written language. At times they might access meaning directly through the written symbol (word) or at other times through the sign code.

Another significant feature of BDE is that the first language, ASL, does not have a written form. Some have argued that this feature will reduce transfer of proficiency from ASL to English (Mayer \& Wells, 1996; RitterBrinton, 1996). The argument assumes, however, that literacy consists only of the reading and writing components of language. A broader definition of literacy, which includes the context of language use, changes the predictions sornewhat. When literacy is defined broadly (to include what some might call communicative competence), it requires a range of abilities from formal, decontextualized language to more conversational language. Literacy becomes the ability to use appropriate language forms depending on the social context. Schley (1992) studied the ability of Deaf children to modify their ASL use in contextualized and decontextualized language situations and found 
that the children did produce different types of language appropriate to the situations. Their literacy-related and metalinguistic skills were part of the deeper structures of ASL, and knowledge of them transferred across languages in bilingual children. By expanding the definition of literacy in this way, bilingual proficiency and literacy would be expected to develop even where one language does not have a written form.

$\mathrm{BDE}$ differs from both bilingual education in heritage languages and bilingual education in second language immersion programs in that the family language background of deaf children is not consistent. Among children born deaf, fewer than $10 \%$ come from families with even one Deaf parent or older Deaf relative (Meadow, 1972; Trybus \& Jensema, 1978). When such relatives do exist, deaf children can acquire ASL and so have opportunities for typical family interactions and socioemotional development. Bilingual programming for this minority of deaf children would follow the typical approach of building on the heritage language, here ASL, and of introducing English as a second language.

For the other $90 \%$ of deaf children, however, the situation is quite different. Here the deaf child is the first deaf person in the family. For the child's parents, encountering deafness in the child is generally unexpected and traumatic. The parents and siblings of deaf children seldom have the ASL communication skills required to provide these children immediate access to the acquisition of a natural language, a circumstance that limits access to the family's cultural knowledge and resources. The children tend to enter kindergarten without much competence in any language, signed or spoken (Johnson et al., 1989). Bilingual programming for these children, therefore, requires that they first develop proficiency in ASL before facilitating acquisition of English as a second language. This is also the case for the growing number of deaf children who immigrate to Canada with their families of many different languages and may or may not have had exposure to a sign language. Similar strategies can be used to establish ASL as a language base and then develop written English skills; however, the need to maintain and incorporate various aspects of the heritage language (either signed or spoken) and culture must also be taken into consideration.

\section{Approaches and Strategies for Literacy Development with Bilingual Children}

The differences described above between BDE and other forms of bilingual education frequently create confusion and inconsistency in the implementation of programs for deaf students. In spite of differences, however, some aspects of orally based bilingual education can be applied to bilingual education with deaf students.

Motivation and self-concept. Developing students' motivation and self-concept is important to any teaching, but it is particularly important with bilin- 
gual students who may not feel that their skills and knowledge are recognized because they cannot easily express what they know verbally. A sense of self-worth is encouraged by accepting the student's most familiar language as equal to any other language. Having faith that second language learners will learn and maintaining high expectations for them is also important.

Literacy in two languages (also called biliteracy) often occurs in a context of unequal power relations, with one or the other literacy becoming marginalized (Hornberger, 1989). This is also true of biliteracy programs with deaf children where English dominates ASL. Factors that contribute to the marginalization of ASL include limited and recent linguistic awareness of ASL, attitudes that deafness is a disability, and lack of a written form for ASL. Furthermore, because of the past denigration of ASL and Deaf culture, it is often necessary to overemphasize the value of ASL for deaf children. In the long term, however, ASL and English should be recognized as separate and distinct languages and valued equally. Emphasizing the value of ASL can be accomplished, for example, by inviting story telling by members of the Deaf community (Israelite et al., 1992) and by teachers constructing, expanding, and modifying stories in ASL. These strategies can motivate students to create their own stories and to take pride in their stories, language, and Deaf culture. Such pride can enable them to feel more confident and ready to learn English.

Language development. Teachers must have a thorough understanding of language development so that they can monitor and sequence the linguistic load they place on the students. A key principle is that language learning is maximized by incorporating language development in the academic curriculum explicitly and systematically (Genesee, 1991).

The value of awareness of the linguistic load on deaf students is illustrated in a study by Mozzer-Mather (1990). The investigator sought to improve deaf students' writing by combining writing process and translation techniques. The students used transcribed English glosses (words) of their signed versions of stories to help them prepare written texts. Although the students' first drafts in English deviated in many respects from conventional standard English, this did not mean that they were unaware of the conventions. Rather, it reflected their difficulty in paying attention to these concerns while juggling concerns about content during the creation of a first draft. Second drafts written with the assistance of glosses to remind them of content were substantially more grammatical than the first drafts. The reduction of the linguistic constraints with regard to vocabulary enhanced the volume, syntactic complexity, and correctness of the participants' writing.

Basic knowledge of a child's first language. Basic knowledge of a child's first language is also necessary in order to be aware of points of linguistic interference or conflict between the two languages. The knowledge helps teachers 
to identify errors that are systemic in nature and can be eliminated by emphasizing the distinction between languages rules. The approach is especially important for teachers of deaf children. Clues to understanding deaf students' linguistic processing may lie in their use of space, facial expression, or body shifting, although these features are not part of written language expression and therefore can easily be overlooked. Deaf children must link new meanings in print with their existing knowledge of language, which is visual rather than auditory.

An understanding of fingerspelling and the rules for sign production, for example, can help in understanding deaf children's invented spelling (Schleper, 1994). The strategy of handshape borrowing or writing the word based on the handshape of the sign may result in spellings that are not easily understood. For example, a child may spell in starting with a $B$ or cat starting with an $F$ based on the handshapes used to produce the signs for these words. Substitutions of letters may also occur based on how closely they resemble each other on the hands, not whether they sound alike.

A case study of a Deaf child by Wilcox (1994) provides another example. Wilcox documented how the child used the phonology of ASL to solve the problems she faced in learning to read. The child created a three-way link between the visual phonetics of signed language, fingerspelling, and English orthography. The ASL handshape represented the meaning of the word, and the fingerspelling helped to link this meaning with the printed representation. It appears that this Deaf child bypassed the phonological system and used a system she could understand. She did so by matching her existing linguistic knowledge of ASL constructs to print, even when her knowledge of ASL was limited or when it conflicted with rules of English. For example, the child learned that the -ing ending in English represented the present progressive tense. She was also aware of the tendency for verb tense to be indicated at the beginning of sentences in ASL. This resulted in her producing sentences that combined elements of the two languages "incorrectly," such as, "-ING ME EAT ME." A teacher without knowledge of ASL grammar might have labeled these productions as language-disordered rather than recognizing them as systematic problem-solving.

Speak, then read. Another general strategy in educating bilingual children is to teach them the spoken form of a language before introducing reading in the language. This practice has been questioned, however, in light of studies where write-first instructional approaches have been more effective for developing literacy in some learners (Mercado, 1991; Wald, 1987). The belief that language develops sequentially from listening, to speaking, to reading, and finally to writing, therefore, does not seem to occur for all students. All language processes may instead develop simultaneously, and practices such as delaying instruction in reading and writing until there is oral mastery of what is to be read in English as a second language are of questionable value, 
serving to limit the learning opportunities rather than enhancing them. The shift away from requiring sequential mastery of literacy skills is promising for deaf students, because many deaf children learn English through reading and writing.

Most models of second-language acquisition emphasize the importance of an internalized phonemic system in oral literacy acquisition processes (Rosner, 1986). But analogies exist for deaf children, who seem to develop an internal representation of their visual language (Brooks, 1978). The process of developing reading skills in deaf children must, therefore, link these internal structures to the grammatical features of written English. Ruiz (1995), in a case study of her Deaf daughter's literacy acquisition, found that the daughter did not need an orally based, internalized phonemic system, nor the phonemic awareness activities or direct phonics instruction that many researchers and teachers consider indispensable.

Allow translation. Bilingual children should be allowed to translate to their first language (ASL) when reading in their second language (English), and the translations should not be considered errors. This is a useful reading strategy for making print meaningful.

One method for using ASL to teach English involves making comparisons and translations between the two languages explicit (Neuroth-Gimbrone \& Logiodice, 1992). The students initially express story content in ASL, and the expressions are videotaped. The production of English writing then becomes a process of transcribing these videotapes. The relationship of spoken to written language needs to be taught, and translation from one language (sign language) to another (written English) can be systematic (Erting, 1992). It appears that more attention should be directed to the nonmanual components of ASL (movement, facial grammar, body shifting), as these convey vital grammatical information that needs to be linked explicitly to the corresponding grammatical features of English (Marshark, 1993).

Emphasize comprehension. In teaching second language learners, teachers should try to make information meaningful and comprehensible (Hudelson, 1994). The core of literacy is the construction of meaning, whether the text is the student's own or written by others (Wells, 1986). The construction of meaning is central whether literacy is occurring in a first or second language.

Studies have documented this principle with deaf students by showing, for example, that deaf students use semantic clues to make sense of difficult grammatical structures (Yurkowski \& Ewoldt, 1986). When they process these sentences, the deaf readers appear to consider what makes sense rather than analyzing the grammatical relationships between words. Unfortunate$l y$, instructional practices with deaf children commonly emphasize the grammatical structures that focus on the deaf students' weaknesses (syntax) and ignore their strengths (semantics). In response to deaf students' difficulties with syntax, many educators simplify text to facilitate reading skills. Yet this 
response may inhibit language growth rather than promote it (Ewoldt, 1984, 1987). Without exposure to a variety of syntactic patterns, deaf children cannot use their most effective strategies (semantics) for mastering the subtleties of syntax. The emphasis on semantic processes, however, must be developed systematically through exposure to appropriate background information, real-life experiences, and the use of syntactically simpler reading materials.

Use the child's first language to ensure comprehension. Written text in the child's second language can be discussed in the child's first language to ensure comprehension of the textual information and to develop vocabulary knowledge in context (Swaffar, 1988). For deaf students this means that instructional conversations can take place in ASL about written English and should also occur in written English about ASL (Erting, 1992). Formal instruction related to higher-order thinking and literary forms have been helpful with deaf students, whose problems occur not only at lexical and sentential levels, but also at broader levels of context (Kretschmer, 1989), such as knowledge of genres, coherence, and author's voice and reader's perspective. Intervention with deaf students should, therefore, include making textual structures and connections more explicit and stimulating reflection by providing appropriate inferential questions. Teachers should use the students' native language in teaching these broader literacy skills, which are necessary for the development of full reading comprehension (Paul \& Quigley, 1987).

Incorporation of culture. Teaching bilingual students also requires understanding their cultural values (Ching, 1976). Incorporating the visually oriented features of Deaf culture is essential in teaching deaf children. Strategies can be as simple as flashing the lights to get attention and using a variety of visual aids when presenting lessons or as complex as developing visual poetry. Besides visual strategies, ASL discourse patterns also influence the most effective method of presenting information. ASL frequently uses a "diamond" discourse strategy, where the main point is presented initially, followed by expansion and background information, and closing with a restatement of the main point (Small \& Philip, 1992). This contrasts with the more typical English discourse strategy of beginning with general information and concluding with the specific point.

Deaf communities operate collectively as opposed to the more individualistic standard common in Canadian culture (Philip, 1987). In the classroom this principle means agreeing as a group on the rules and expectations for behavior, rather than the teacher telling the students what the rules are. It also means deciding by consensus where possible rather than by majority rule. A belief in collectivism also fosters peer teaching. Students are encouraged to work as a group so that concepts are understood by all and tasks are completed by everyone. Although such collaboration may be good 
teaching practice with any group of children, interactional activities have been especially beneficial for second language learning (Genesee, 1991).

Use of native language or cultural role models. An essential element of BDE is having teachers who are true role models for Deaf culture. In practice such teachers need to be Deaf themselves, as well as fluent signers of ASL and skilled readers of written English. Several studies have emphasized how Deaf parents and teachers naturally elicit more interaction with deaf children because they are so much more visually attuned than are hearing people (Erting, 1988; Mather, 1989; Padden \& Ramsey, 1996).

The study by Mather (1989), for example, compared a Deaf and a hearing educators' presentation of a story to deaf children. The Deaf teacher's fluency in ASL allowed her to modify her register to meet the diverse language needs of all the students in the group and to enter into truly meaningful conversation with them. Many of the strategies she used, such as asking Wh- questions rather than yes-no questions, were not unique to Deaf teachers, but were good teaching practices in general. They apparently proved more difficult, however, for the hearing educator, whose limited ASL skills and stronger auditory orientation may have caused her to rely on more structured activities that controlled the language interaction.

Similarly, hearing parents reading with their deaf children were found to be more structured in approach and to create fewer links between the book and personal experiences than parents reading with their hearing children (Paul \& Quigley, 1987). The differences presumably limit the development of pre-reading skills in deaf children, and may be linked to difficulties with meaningful conversations as well. To understand how hearing parents can best facilitate the literacy skills of their deaf children, therefore, learning from Deaf families is necessary (Erting, 1992), where more natural interaction occurs.

\section{Conclusion}

The more the learning contexts allow students to draw on the three continua of biliterate development, that is, both oral and written, both receptive and productive, both first and second language skills, the greater the chances for their biliterate development. (Hornberger, 1990, p. 3)

This quotation was written about oral bilingualism, but it can just as easily refer to the bilingual education of Deaf students. In learning a second language - whether spoken, signed, or written - the traditional pedagogical progression of listening, speaking, reading, and finally writing is no longer considered the only path to literacy. The newer multiple approaches bode well for deaf children, who simply cannot access all the steps along the traditional path, even if it were educationally desirable. At the same time, the 
success of a bilingual approach to Deaf education provides important support for advocates of more contextually sensitive teaching strategies (Evans, 1999). Literacy in a first language of Deaf people, ASL, gives Deaf students the initial tools of experience, meaningful concepts, and deeper linguistic awareness, which facilitate later learning of written English.

Although these ideas may seem wise, or even obvious, to many ESL instructors, they often seem less so to professionals working in the fields of medical rehabilitation and special education, where inclusion of individuals with disabilities is overwhelmingly (and usually rightly) the dominant philosophy. To make the bilingual perspective work for those professionals requires a paradigm shift that is currently only partly complete. In particular, children who are deaf must be regarded less as globally disabled than as culturally different. This paradigm does not deny that Deaf people face problems in relating to the world of hearing people, but it does suggest that these problems have important similarities to the problems of other cultural and linguistic minorities in English-speaking societies.

\section{Note}

${ }^{1}$ Throughout this article, which describes studies that view deaf children and their language from a cultural rather than the usual disability perspective, conventions are applied in labeling deaf children that tend to differ from standard Canadian usage. Following the convention proposed by Woodward (1972), we use the lower-case deaf when referring to the audiological condition of not hearing, and the upper-case Deaf when referring to deaf children and adults who share a language-American Sign Language (ASL) - and a culture. This is similar to the Canadian convention of capitalizing the names of linguistic minority groups, such as Filipino, Cree, or Ojibway. In addition, deaf is also used inclusively to refer to all children with hearing losses including those who may eventually become Deaf children or adults.

\section{Acknowledgments}

The authors would like to thank Sandie Kouritzin and Patrick Mathews, as well as TESL Canada Journal's anonymous reviewers for their helpful comments on earlier drafts of this article.

\section{The Authors}

Charlotte Evans is an assistant professor in the area of special education at the University of Manitoba. Her research interests include deaf education, language acquisition, and literacy development. She can be reached at evans@ms.umanitoba.ca.

Kevin Seifert has been teaching educational psychology at the University of Manitoba for 25 years. His research interests concern the belief systems of teachers working with young children. $\mathrm{He}$ is the author of numerous publications and textbooks in this area, including his most recent book Constructing a Psychology of Teaching and Learning.

\section{References}

Baker, C., \& Battison, R. (1980). Sign language and the deaf community: Essays in honor of William C. Stokoe. Washington, DC: National Association of the Deaf.

Bellugi, U., Poizner, H., \& Klima, E. (1989). Language, modality, and the brain. Theoretical Issues in Neurological Science, 12(10), 380-388. 
Brooks, P. (1978). Some speculations concerning deafness and learning to read. In L.S. Liben (Ed.), Deaf children: Developmental perspectives (pp. 77-91). New York: Academic Press.

Ching, D.C. (1976). Reading and the bilingual child. Newark, DE: International Reading Association.

Collier, V. (1989). How long? A synthesis of research on academic achievement in a second language. TESOL Quarterly, 23, 509-531.

Cummins, J. (1984). Bilingualism and special education: Issues in assessment and pedagogy. San Diego, CA: College Hill Press.

Davies, S. (1991). The transition toward bilingual education of Deaf children in Sweden and Denmark: Perspectives on language. Sign Language Studies, 71, 169-195.

Edelsky, C. (1989). Putting language variation to work for you. In P. Rigg \& V.G. Allen (Eds.), When they don't all speak English: Integrating the regular student in the ESL classroom (pp. 96-107). Urbana, IL: National Council of Teachers of English.

Erting, C.J. (1988). Acquiring linguistic and social identity: Interactions of deaf children with a hearing teacher and deaf adult. In M. Strong (Ed.), Language learning and deafness (pp. 154-168). New York: Cambridge University Press.

Erting, C.J. (1992). Deafness and literacy: Why can't Sam read? Sign Language Studies, 75 , $97-112$.

Evans, C.J. (1999). Literacy development in Deaf students: Case studies in bilingual teaching and learning. Unpublished doctoral dissertation, University of Manitoba.

Ewoldt, C. (1984). Problems with rewritten materials as exemplified by "To build a fire." American Annals of the Deaf, 129(3), 23-28.

Ewoldt, C. (1987, March). Reading tests and the deaf reader. Perspectives, 21-24.

Genesee, F. (1991). Second language learning in school settings: Lessons from immersion. In A.G. Reynolds (Ed.), Bilingualism, multiculturalism, and second language learning: The McGill conference in honour of Wallace E. Lambert (pp. 74-80). Mahwah, NJ: Erlbaum.

Genesee, F. (Ed.). (1994). Educating second language children: The whole child, the whole curriculum, the whole community. Cambridge, MA: Cambridge University Press.

Hatano, G. (1986). How do Japanese children learn to read? Orthographic and eco-cultural variables. In B. Foorman \& A. Seigel (Eds.), Acquisition of reading skills: Cultural constraints and cognitive universals (pp. 114-121). Mahwah, NJ: Erlbaum.

Hoffmeister, R., \& Wilbur, R. (1980). Development: The acquisition of sign language. In H. Lane \& F. Grosjean (Eds.), Recent perspectives on American Sign Language (pp. 61-78). Mahwah, NJ: Erlbaum.

Hornberger, N.H. (1989). Creating successful learning contexts for biliteracy: Alienation and connection. Language Arts, 66, 392-406.

Hornberger, N.H. (1990). Creating successful learning contexts for biliteracy. Penn Working Papers in Educational Linguistics, 6(1), 125-133.

Hudelson, S. (1994). Literacy development of second language children. In F. Genesee (Ed.), Educating second language children: The whole child, the whole curriculum, the whole community (pp. 129-158). Cambridge, MA: Cambridge University Press.

Israelite, N., Ewoldt, C. \& Hoffmeister, R. (1992). Bilingual/Bicultural education for deaf and hard-of-hearing students: $A$ review of the literature on the effects of native sign language on majority language acquistion. Toronto, ON: Ministry of Education.

Johnson, R., Liddell, S., \& Erting, C.J. (1989). Unlocking the curriculum: Principles for achieving access in deaf education. Washington, DC: Gallaudet University Press.

Klima, E., \& Bellugi, U. (1979). The signs of language. Cambridge, MA: Harvard University Press.

Kouritzin, S. (1999). Facelt]s of language loss. Mahwah, NJ: Erlbaum.

Kretschmer, R. (1989). Pragmatics, reading and writing: Implications for hearing impaired individuals. Topics in Language Disorders, 9(4), 17-32.

Marshark, M. (1993). Psychological development of Deaf children. New York: Oxford University Press. 
Mahshie, S. (1995). Educating deaf children bilingually. Washington, DC: Gallaudet University Press.

Mather, S. (1989). Visually oriented teaching strategies with deaf preschool children. In C. Lucas (Ed.), The sociolinguistics of the Deaf community (pp. 163-187). New York: Academic Press.

Mayer, C., \& Wells, D. (1996). Can the linguistic interdependence theory support a bilingual-bicultural model of literacy education for deaf students? Journal of Deaf Studies and Deaf Education, 1,93-107.

Meadow, K.P. (1972). Sociolinguistics, sign language, and the Deaf sub-culture. In T.J. O'Rourke (Ed.), Psycholinguistics and Total Communication: The state of the art (pp. 113-125). Washington, DC: American Annals of the Deaf.

Meier, R. (1991). Language acquistion by Deaf children. American Scientist, 79(1), 60-70.

Mercado, C.I. (1991) Native and second language liferacy: The promise of a new decade. In A.N. Ambert (Ed.), Bilingual education and English as a second language: A research handbook 1988-1990 (pp. 245-267). New York: Garland.

Mozzer-Mather, S. (1990). A strategy to improve Deaf students' writing through the use of glosses of signed narratives. Washington, DC: Gallaudet University Press.

Neuroth-Gimbrone, C., \& Logiodice, C. (1992). A cooperative bilingual language program for deaf adolescents. Sign Language Studies, 74, 79-91.

Padden, C., \& Ramsey, C. (1996, September). ASL and reading ability in deaf children. Paper presented at the Theoretical Issues in Sign Language Research Conference, Montreal.

Paivio, A. (1991). Mental representation in bilinguals. In A.G. Reynolds (Ed.), Bilingualism, multiculturalism, and second language learning: The McGill conference in honour of Wallace $E$. Lambert (pp. 104-117). Mahwah, NJ: Erlbaum.

Paul, P.V., \& Quigley, S. (1987). Using American Sign Language to teach English. In P. McNally, S. Rose, \& S. Quigley (Eds.), Language learning practices with deaf children (pp. 139-166). Boston, MA: College-Hill Press.

Peal, E., \& Lambert, W.E. (1962). The relation of bilingualism to intelligence. Psychological Monographs: General and Applied, 76, 1-23.

Petitio, L.A., \& Marentette, P.F.(1991). Babbling in the manual mode: Evidence for the ontogeny of language. Science, 251, 1493-1496.

Philip, M.J. (1987, May). Cross-cultural awareness. Paper presented at the meeting of the Registry of Interpreters for the Deaf, Minneapolis.

Reynolds, A.G. (1991). The cognitive consequences of bilingualism. In A.G. Reynolds (Ed.), Bilingualism, multiculturalism, and second language learning: The McGill conference in honour of Wallace E. Lambert (pp. 105-118). Mahwah, NJ: Erlbaum.

Ritter-Brinton, K. (1996). The great ASL/MCE debate-What it's telling us and what it's costing us. The CAEDHH Journal, 22, 24-34.

Rosner, J. (1986). Phonological skills and learning to read and write: Reactions and implications. In B. Foorman \& A. Seigel (Eds.), Acquisition of reading skills: Cultural constraints and cognitive universals (pp. 201-225). Mahwah, NJ: Erlbaum.

Ruiz, N.T. (1995). A young deaf child learns to write: Implications for literacy development. Reading Teacher, 49(3), 206-217.

Schleper, D.R. (1994). Does your F want to Y? How Deaf children use invented spelling. Whole Language Umbrella, 6(2), 16-17.

Schley, S. (1992, March). Bilingual literacy in Deaf children: Towards a definition. Paper presented at the meeting of Teaching English to Speakers of Other Languages, Vancouver.

Small, A., \& Philip, M.J. (1992, March). Bilingual-bicultural education for Deaf children. Paper presented at the meeting of Teaching English to Speakers of Other Languages, Vancouver.

Strong, M. (1988). A bilingual approach to the education of young deaf children: ASL and English. In M. Strong (Ed.), Language learning and deafness (pp. 113-129). Cambridge, MA: Cambridge University Press. 
Swaffar, J.K. (1988). Readers, texts, and second languages. Modern Language Journal, 72, 123-149.

Trybus, R., \& Jensema, C. (1978). Communication patterns and education achievement of hearing impaired students. Washington, DC: Office of Demographic Studies, Series T, No. 2, Gallaudet College.

Vygotsky, L.S. (1978). Mind in society. Cambridge, MA: Harvard University Press.

Wald, B. (1987). The development of writing skills among high school students. In S.G.

Goldman \& H.T. Trueba (Eds.), Becoming literate in English as a second language (pp. 79-92). Norwood, NJ: Ablex.

Wells, G. (1986). The meaning makers. Portsmouth, NH: Heineman.

Wilcox, S. (1994). Struggling for a voice: An interactionist view of language and literacy in Deaf education. In V. John-Steiner, C.P. Panofsky, \& L.W. Smith (Eds.), Sociocultural approaches to language and literacy: An interactionist perspective (pp. 109-138). Cambridge, MA: Cambridge University Press.

Wong Fillmore, L. (1991). When learning a second language means losing the first. Early Childhood Research Quarterly, 6, 323-346.

Woodward, J. (1972). Implications for sociolinguistics research among the deaf. Sign Language Studies, 1, 1-7.

Yurkowski, P., \& Ewoldt, C. (1986). A case for the semantic processing of the deaf reader. American Annals of the Deaf, 131, 243-247. 